\title{
УПРАВЛЕНИЕ РОЖДАЕМОСТЬЮ В КОНТЕКСТЕ РАЗВИТИЯ СОЦИАЛЬНО-ЭКОНОМИЧЕСКИХ СИСТЕМ
}

\author{
(c) 2021 Родионов Дмитрий Григорьевич \\ доктор экономических наук, профессор, Высшая инженерно-экономическая школа \\ Санкт-Петербургский политехнический университет Петра Великого, Россия, Санкт-Петербург \\ E-mail:dmitry.rodionov@spbstu.ru \\ (c) 2021 Колесников Антон Александрович \\ Высшая инженерно-экономическая школа \\ Санкт-Петербургский политехнический университет Петра Великого, Россия, Санкт-Петербург \\ E-mail: kolesnikov2.aa@edu.spbstu.ru \\ (c) 2021 Конников Евгений Александрович \\ кандидат экономических наук, доцент, Высшая инженерно-экономическая школа \\ Санкт-Петербургский политехнический университет Петра Великого, Россия, Санкт-Петербург \\ E-mail: konnikov.evgeniy@gmail.com
}

Актуальность исследуемой проблемы крайне велика. Необходимо понимать, каким образом влиять на рождаемость, чтобы повысить уровень общественного благосостояния, и нужно ли влиять вовсе. Колоссальные суммы из бюджетов различных государств тратятся на программы по решению демографических проблем. Нужно осознать и довести до общественности, интеллектуальной элиты и властей особенности данного вида государственной политики. Цель исследования состоит в том, чтобы оценить, насколько велико влияние макроэкономических факторов на уровень рождаемости и составить стройную систему выводов, почему рождаемость изменяется именно так и никак иначе. В данной работе был проанализирован массив экономической информации вкупе с показателями рождаемости в США. Это было сделано для того, чтобы количественно оценить влияние факторов на результат. Результаты исследования будут полезны прежде всего политикам и государственным деятелям в области демографии, а также людям, изучающим такие же или схожие показатели и зависимости.

Ключевые слова: рождаемость, социально-экономическое развитие, регрессионный анализ, уровень благосостояния.

Рождаемость - это, несомненно, важный демографический процесс, который во многом обусловливает воспроизводство населения. В настоящее время в нашей стране исследования в области рождаемости весьма актуальны в связи с неблагоприятной демографической обстановкой. Статистический анализ рождаемости играет весьма важную роль в исследовании воспроизводства населения, при характеристике демографической ситуации, как в регионе, так и в стране в целом, прогнозировании численности населения и обосновании состава мероприятий демографической политики. Существует множество факторов, влияющих на рождаемость. Среди них:

- Общий уровень благосостояния, повышение которого способствует увеличению средней продолжительности жизни людей и соответ-

ственно «старению» населения в целом с вытекающими из него демограф. последствиями

- Высокий уровень благосостояния подразумевает высокий уровень образованности. Коэффициент рождаемости снижается, когда женщина имеет возможность получить образование, и повышается, когда она лишена ее.

- Получение образования открывает большие шансы трудоустройства вне дома. Высокий уровень благосостояния подразумевает также высокую стоимость образования и воспитания детей. В развитых странах, где детский труд запрещен законом, «цена» ребенка настолько высока, что влияет на уменьшение к. рождаемости.

- Система государственного и частного социального обеспечения. При наличии такого обеспечения вовсе не обязательно иметь много детей, чтобы не тревожиться за старость. 
- Уровень урбанизации. У городского населения рождаемость ниже, чем у сельских жителей, которым дети помогают в с/х работах, заготовке дров, выполнении многих домашних дел.

- Брачность, разводимость и семейное положение.

Цель исследования - системное описание проблемы влияния экономических показателей на уровень рождаемости в США. По результатам анализа теоретико-методологического базиса могут быть сделаны следующие выводы:

1. Уровень безработицы оказывает непосредственное влияние на коэффициент рождаемости.

2. Существуют разные факторы, влияющие на рождаемость в регионах России. Было отмечено повышение степени влияния безработицы в регионах на процессы рождаемости как альтернативы трудовой деятельности. На основе исследования точек перегиба трендов факторного влияния сделаны выводы о явлениях конвергенции темпов рождаемости между периферийными регионами и центрами экономического развития, а также об эффективности введения института материнского капитала.

3. Следует изучить зарубежный опыт регулирования демографической политики и возможности его реализации в российской федерации. Среди экономических мер, воздействующих на социально-экономические условия, обычно понимаемые как факторы рождаемости, наиболее распространены разнообразные пособия и надбавки, а также налоговые льготы. K экономическим мерам относятся такие также различные непрямые льготы транспортные, жилищные, образовательные. Самым обычным ответом на падение рождаемости, особенно в странах с развитой системой семейного страхования, было повышение уровня материальной помощи семьям.

4. Экономика и демография тесно взаимосвязаны: возрастно-половой состав населения и его составляющие прямо влияют на процесс производства, распределения производимых обществом благ. Следовательно, проблемы демографического состояния страны прямо влияют на ее экономику. Важнейшей составляющей каждой страны, основой крепкого государства, обеспечивающей его надежное существование и развитие, является население. К сожалению, за последние несколько десятков лет в ряде экономически развитых стран, равно как и в нашей стране, происходящие демографические изменения не характеризуются с положительной стороны.

5. Весомое влияние на демографический процесс оказывает государство, через проведение демографической политики.

Изменение демографической ситуации в лучшую сторону и быстрыми темпами практически невозможно. Ведь демографическое поведение человека обусловлено не биологическими процессами, но и идейно-духовным состоянием. В настоящее время более результативным оказывается способ стимулирования рождаемости не денежными выплатами, а формированием для семей достойной для существования инфраструктуры. Помощь такого характера снижает усилия родителей в проявлении заботы о своем потомстве, не выводит их из зоны собственного комфорта и снижает барьер для желания приумножить размер своей семьи.

Возможно предположить, что главная причина неблагоприятной демографической ситуации состоит в отсутствии понимания высших ценностей и идей проживания в родной стране, непонимания направленности своего государственного развития, при постепенной утрате национальных традиций и устоев. Сложившееся положение вызывает у населения состояние психологического неудобства, которое проявляется в демографическом поведении. Претворение в жизнь оптимистического сценария экономического роста блокируется нарастающими на рынке труда структурными диспропорциями из-за сокращения численности населения в трудоспособном возрасте, что ограничивает возможности вклада человеческого потенциала в создание национального богатства. Такая ситуация со временем приведет к возрастанию доли работников старших возрастов, не владеющих современным профессионально-квалификационным профилем.

Если говорить о ситуации с рождаемостью в Америке, то можно сделать несколько выводов:

1. На протяжении многих лет мы наблюдали, как численность населения Америки не переставала увеличиваться. Рост населения происходил быстрыми темпами. Прежде всего, это было связано с высокой рождаемостью и массовой иммиграцией.

2. На сегодняшний день можно констатировать, что рождаемость в Америке упала до уровня великой депрессии 1930-х гг. Если рань- 
ше абсолютный прирост населения США увеличивался, то в последние годы он стал снижаться. В начале нашего столетия средний годовой прирост численности населения США составлял $2,5 \%$, а сегодня менее $1 \%$. В связи с этим, многие исследователи говорят о том, что постепенно прирост населения может свестись к нулю. Важным является то, что снижение прироста охватило все районы страны и практически все группы населения.

Показатели, используемые в модели множественной регрессии, должны соответствовать следующим признакам:

1. В модели должны быть только суще- ственные факторы, непосредственно формирующие результат.

2. Факторы и результат должны быть количественно измерены.

3. Факторы не должны находиться в тесной взаимосвязи друг с другом.

По результатам анализа матрицы коэффициентов частной корреляции между факторами, ряд показателей были удалены из модели, так как модуль их коэффициента корреляции был больше 0,7. Были исключены:

1. $\mathrm{X}_{4}$ Доля в совокупном доходе 2й квантильной группы.

2. $\mathrm{X}_{7}$ Процентная ставка.

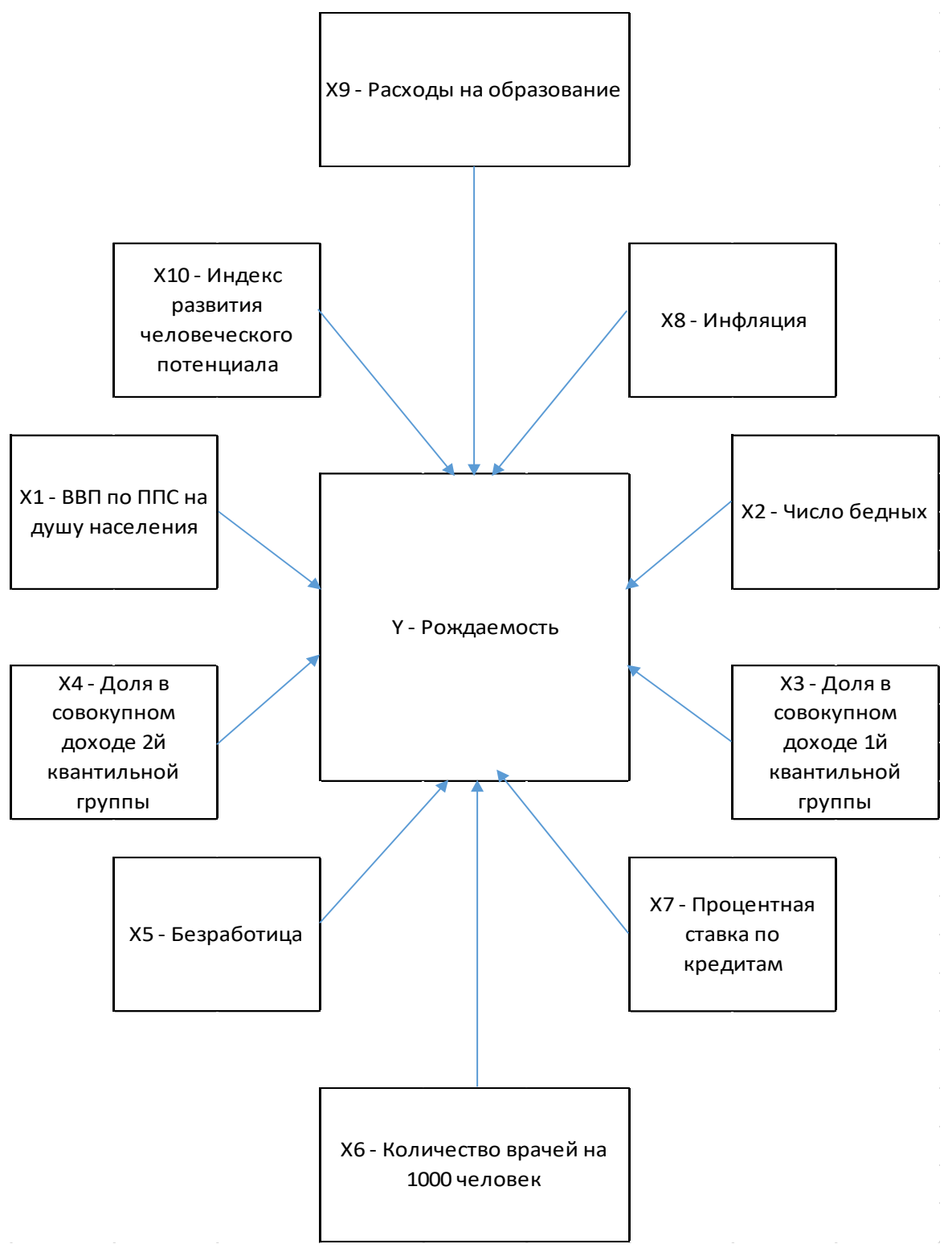

Рисунок 1. Концептуальная модель исследования 
3. $\mathrm{X}_{9}$ Процент расходов на образование.

Изначальная модель имеет крайне высокую степень объясненной дисперсии $\mathrm{Y}$ через $\mathrm{X}_{\mathrm{j}}: \mathrm{R}^{2}=$ 0,94. Первичное уравнение регрессии представлено следующим образом:

$$
Y=64,86-0,00012 * X_{1}-0,23 * X_{2}-3,34 * X_{3}
$$$$
+0,04 * X_{5}+0,29 * X_{6}+0,06 * X_{8}-31,62 * X_{10}
$$

B процессе оптимизации были пошагово удалены показатели, имеющие наибольший p-level в каждой итерации. Были исключены:

1. $\mathrm{X}_{2}-$ Процент людей, живущих меньше чем на $\$ 5$ в день

2. $\mathrm{X}_{6}-$ Процент врачей.

3. $\mathrm{X}_{5}-$ Безработица.

4. $\mathrm{X}_{8}-$ Инфляция.

$\mathrm{B}$ результате оптимизации была получена модель, в которой (p-level)j имеет значение меньше принятого нами ранее $(0,1)$. Финальная оптимизированная формула уравнения регрессии имеет следующий вид:

$$
Y=59,89-0,00013 * X_{1}-2,81 * X_{3}-28,25 * X_{10}
$$

Рассмотрим динамику фактических и теоретических значений признака-результата (рисунок 2).

График показывает, насколько точно уравнение, выведенное ранее, описывает фактическую ситуацию. Анализируя график, можно сделать следующие выводы:
1. Визуально заметно, что ряды «Ү фактический» И «Ү теоретический» находятся на крайне близком расстоянии на протяжение всего временного ряда. Это может помочь составить априорный вывод о том, что модель регрессии построена корректно.

2. Структурных выбросов на графике не замечено.

3. Структурных разрывов на графике не замечено.

Рассмотрим график остатков (рис. 3). Из графика видно, что модель не имеет гетероскедастичности: в остатках не наблюдается какого-либо тренда. Определенные показатели могут подсказать, достоверно ли построена модель множественной регрессии:

1. Коэффициент детерминации модели $\left(\mathrm{R}^{2}\right)$ составил 0,94. Это означает, что данная регрессионная модель описывает 94\% дисперсии результирующего признака.

2. Средняя ошибка аппроксимации находится на приемлемом уровне $-1,7 \%$. Это означает, что в среднем расчетное значение Ү отличается от фактического на $1,7 \%$.

3. F-критерий имеет довольно высокое значение $-185,84$. Это значит, что признается статистическая значимость уравнения.

4. Р-значения у готовой модели крайне малы. Каждый из них находится в диапазоне $[0 ; 0,1]$.

Подтвержденная концептуальная модель представлена на рисунке 4 .

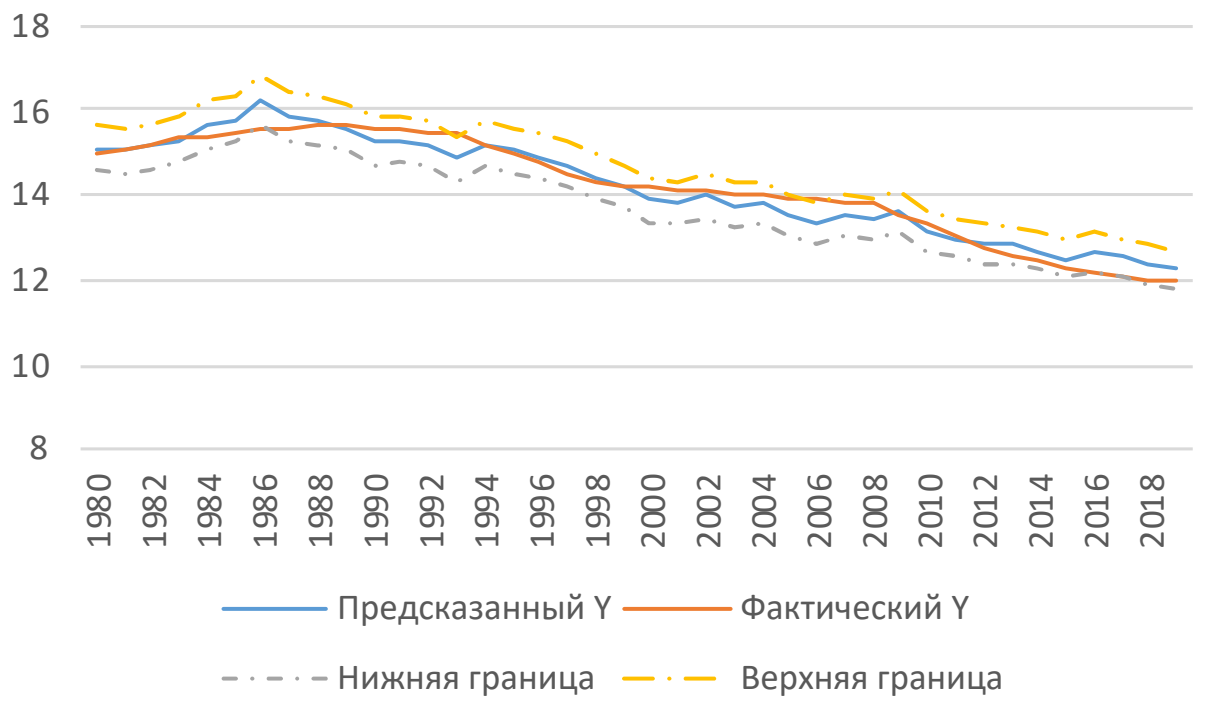

Рисунок 2. График сопоставления фактических и теоретических значений Y 


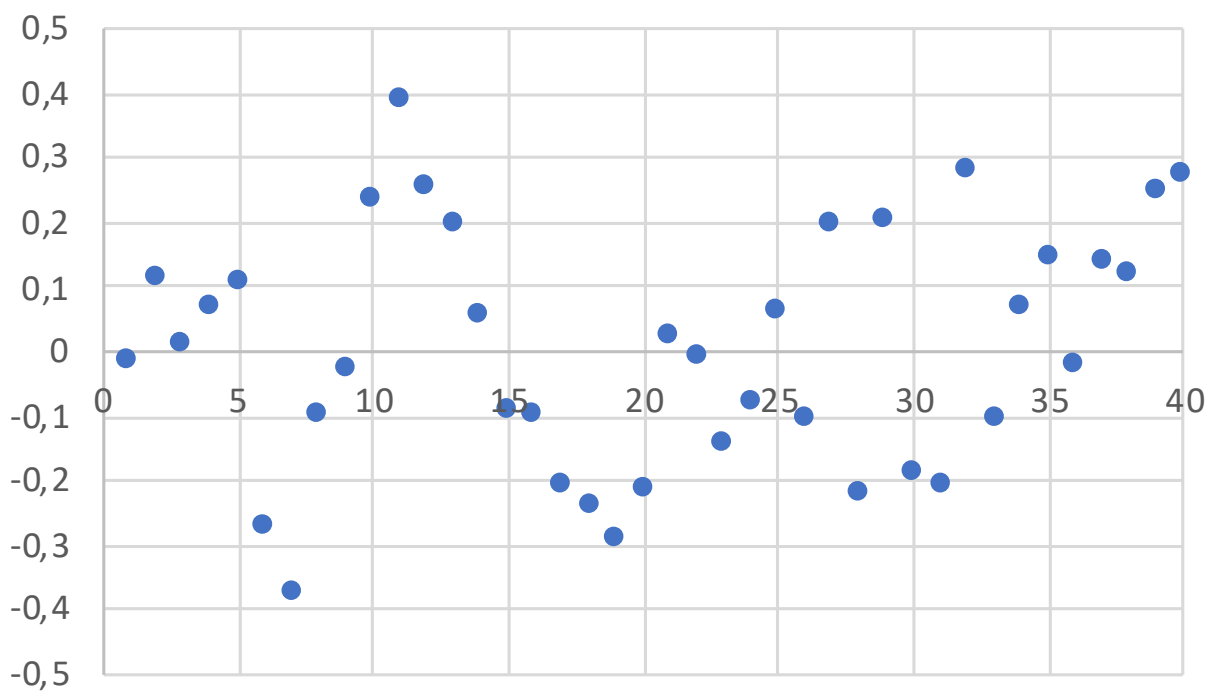

Рисунок 3. График остатков

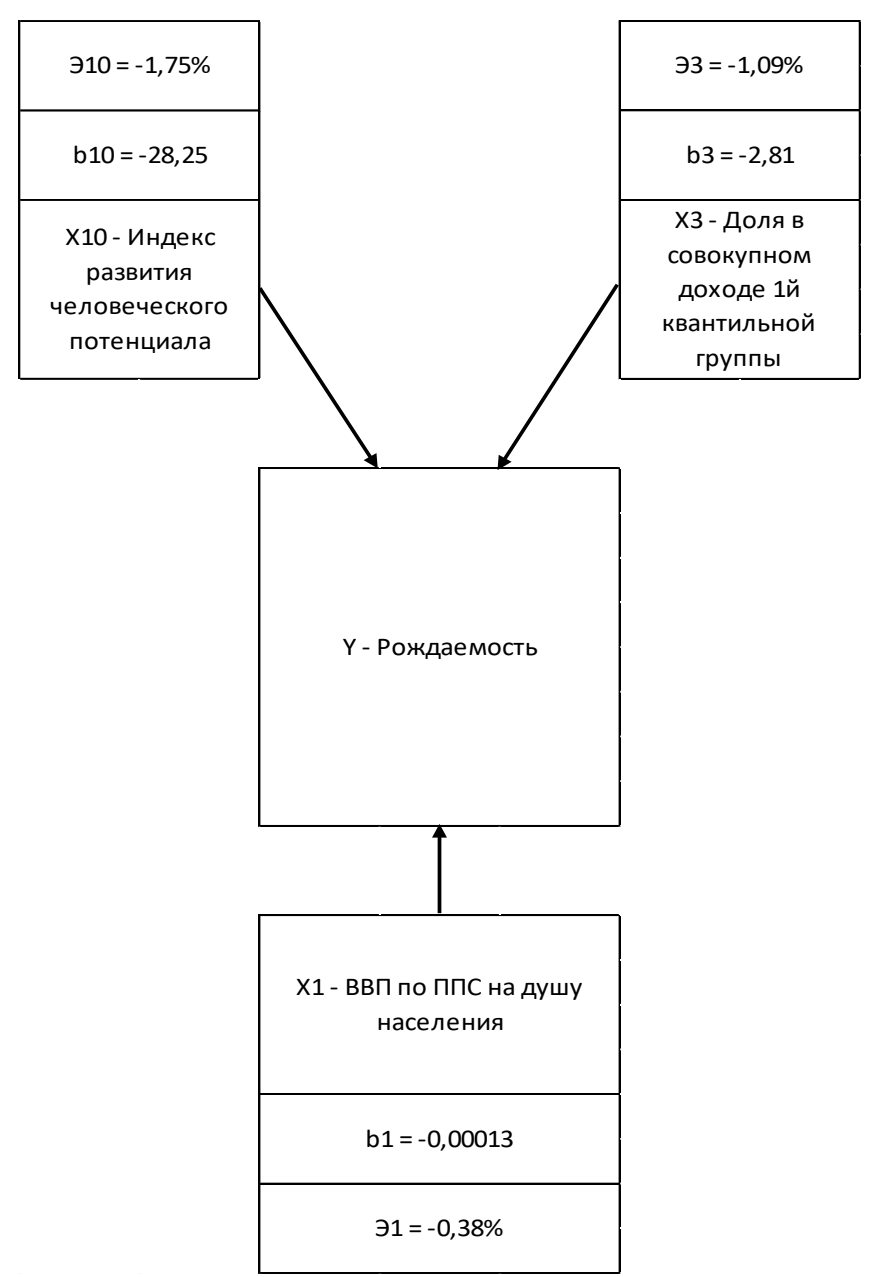

Рисунок 4. Подтвержденная концептуальная модель 
Рассчитанные показатели эластичности нуждаются в объяснении. Выводы относительно коэффициентов эластичности:

1. Среди указанных в таблице факторов наибольшее влияние на Рождаемость имеет $\mathrm{X}_{10}$ (ИРПЧ). При увеличении этого показателя на $1 \%$ Рождаемость падает на 0,69\% - 1,49\%.

2. Второй по силе влияния на рождаемость показатель - Доля в совокупном доходе 1й квантильной группы $\left(\mathrm{X}_{3}\right)$. При его увеличении на $1 \%$ Рождаемость падает на 0,41\% - 3,09\%.

3. Самый слабый из признаков, влияющих на Y - ВВП по ППС на душу населения $\left(\mathrm{X}_{1}\right)$. Его изменение на $1 \%$ влечет к изменению Рождаемости на $0,14 \%$ - 0,62\% в противоположную сторону.

Таким образом граждане США (впрочем, как и многих других стран, имеющих тенденцию к развитию экономики) стали переходить от традиционного семейного уклада к более свободному. Они перестали ставить рождение детей на первое место в своей жизни и начали отдавать предпочтение другим сферам. Исходя из анализа работы видно, что один из наиболее часто используемых показателей развития благосостояния - ВВП на душу населения - неумолимо рос на протяжение последних 40 лет (впрочем, ранее была такая же тенденция). В то же время коэффициенты эластичности говорят о том, что при росте ВВП на душу населения на $1 \%$, Рождаемость в среднем падает на 0,38\%. Следовательно, можно сделать вывод о том, что чем люди в среднем богаче, тем меньше уровень Рождаемости в стране. Исходя из показателей и коэффициентов эластичности нашей модели множественной регрессии можно сказать, что на рождаемость влияет не только общий уровень богатства, выраженный в ВВП на душу населения, но и доля совокупного богатства, принадлежащего самым бедным. При увеличении доли в совокупном доходе первой квантильной группы на 1\%, Рождаемость падает на в среднем на $1,9 \%$. Это опять же связано с тем, что повышение качества жизни бедных приводит к тому, что им уже не так важно заводить детей, которые в будущем могут стать помощниками.

С ростом благосостояния американцев изменились их ценности: новый мир, предоставляющий множество возможностей открыл новые пути достижения жизненного счастья. Сейчас многие предпочитают карьеру семейной жизни и воспитанию детей. Рождаемость в современном американском обществе снижается не первый год. На это влияет изменение общественной атмосферы, а именно перемещение фокуса внимания от заведения детей к другим формам самореализации. На уменьшение рождаемости также влияет и уменьшение младенческой и детской смертности. С развитием медицины смертность среди детей имела тенденцию к уменьшению, поэтому родители перестали заводить по 5-7 детей (а то и больше) в надежде на то, что хотя бы некоторые из них доживут до трудоспособного возраста. Увеличение доли городского населения также повлияло на рождаемость. Горожане, как правило, заводят меньше детей, так как им не нужны помощники на подсобном или фермерском хозяйстве. В течение последних десятилетий с беспрецедентным ростом крупных городов по всему миру наблюдается значительное снижение уровня рождаемости. Отдельные специалисты в области демографии убеждены в том, что факторы, привлекающие людей в мегаполисы, такие как доступность образования, условия труда для женщин и возможности для планирования семьи, могли сыграть свою роль в этом снижении.

\section{Библиографический список}

1. Гокова О.В. Опыт реализации региональной демографической политики в развитых странах мира // Вестник Омского университета. Серия: Экономика. 2011. № 1. С. 74-80.

2. Гундаров И. А. Новая стратегия повышения рождаемости // История и современность. 2009. № 1. С. $115-129$.

3. Денисенко М.Б. Может ли помочь развитым странам замещающая миграция? // Мир России. Социология. Этнология. 2003. Т. 12. № 3. С. 147-156.

4. Елохин А. П. Некоторые вопросы экологических и демографических проблем в мире и в России // Евразийский союз ученых. 2016. № 1-5 (22). С. 163-180.

5. Елохин А.П., Болдырева М. А., Таболич В. А. Демографическая ситуация в мире и в России // Глобальная ядерная безопасность. 2015. № 1 (14). С. 10-26. 
6. Ершова А.В., Родионов Д.Г., Конников Е.А., Конникова О.А. Системный анализ привлекательности банков для представителей вип-сегмента потребителей в рамках цифровой информационной среды // Экономические науки. 2021. № 194. С. 60-73.

7. Истомина К. С. Влияние показателей на коэффициент рождаемости в регионах // Вестник науки и образования. 2015. № 2 (4). С. 60-63.

8. Казенин К.И. Рождаемость в семьях мигрантов: данные, гипотезы, модели (обзор зарубежных исследований) // Демографическое обозрение. 2017. Т. 4. № 4. С. 1-79.

9. Клупт М.А. Переосмысливая современную историю рождаемости: семья, государство и мир-система // Демографическое обозрение. 2018. Т. 5. № 3. С. 6-24.

10. Конников Е.А., Терентьева Д.А., Конникова О.А. Анализ уровня устойчивого потребления в контексте цифровой информационной среды // Экономические науки. 2020. № 192. С. 114-125.

11. Костин А.И. Демографические проблемы и здоровье человека в политике глобальных изменений // Вестник Московского университета. Серия 12: Политические науки. 2005. № 4. С. 48-63.

12. Куликова С.Н. Влияние социальных ценностей на демографию // Социальные и гуманитарные науки. Отечественная и зарубежная литература. Серия 2: Экономика. Реферативный журнал. 2002. № 1. С. 134-138.

13. Курушина Е.В., Дружинина И.В. Исследование динамики факторного влияния на рождаемость населения России // ЭТАП: экономическая теория, анализ, практика. 2016. № 5. С. 123-137.

14. Магомедов М.А. Зарубежный опыт регулирования демографической политики и возможности его реализации в Российской Федерации // Вопросы структуризации экономики. 2014. №3. С. 80-83.

15. Мяготина Е.Д., Невежин В.П. Влияние уровня безработицы на рождаемость в России // Международный научно-исследовательский журнал. 2020. № 4-2 (94). С. 30-35.

16. Овод А.И. Исследование влияния экономических факторов на уровень рождаемости в странах Европы // Азимут научных исследований: экономика и управление. 2018. Т. 7. № 4 (25). С. 218-221.

17. Процентная ставка по кредитам.- Текст: электронный // Knoema: [сайт].- URL: https://knoema.ru/atlas/ Соединенные-Штаты-Америки/topics/Экономика/Финансовый-сектор-Процентные-ставки/Процентнаяставка-по-кредитам (дата обращения: 05.11.2020).

18. Родионов Д.Г., Конников Е.А., Грачева А.А. Анализ системного влияния динамики развития информационных технологий на трансформацию рынка труда // Вестник Воронежского государственного университета. Серия: Системный анализ и информационные технологии. 2020. № 4. С. 64-80.

19. Родионов Д.Г., Конников Е. А., Мугутдинов Р. М. Системный анализ конкурентоспособности цифрового предприятия в рамках информационной среды // Экономические науки. 2020. № 193. С. 394-401.

20. Рудакова Р. П. Демографическая ситуация и качество жизни населения в мире и в России // Вестник Ленинградского государственного университета им. А. С. Пушкина. 2009. Т. 6. № 3. С. 72-82.

21. Рыбаковский Л. Л. Факторы депопуляции в России // Народонаселение. 2013. № 3 (61). С. $004-019$.

22. Соловьева Е. С. Регулирование рождаемости как проблема мировой политики // Известия Алтайского государственного университета. 2011. № 4-1 (72). С. 269-272.

23. Суммарный коэффициент рождаемости.- Текст: электронный // Knoema: [сайт]. - URL: https://knoema.ru/ atlas/Соединенные-Штаты-Америки/topics/Демография/Рождаемость/Коэффициент-рождаемости (дата обращения: 05.11.2020).

24. Текущие расходы на образование.- Текст: электронный // Knoema: [сайт].- URL: https://knoema.ru/ atlas/Соединенные-Штаты-Америки/topics/Образование/Финансирование-образования/Расходы-наобразование-percent-от-ВНД (дата обращения: 05.11.2020).

25. Тюменщева Г.И. Демографическая политика как фактор национальной безопасности // Вестник Омского юридического института. 2009. № 2 (11). С. 20-25.

26. Чан T.T.T., Конников Е.А. Автоматизированная параметрическая модель нормирования бизнеспроцессов на предприятиях деревообрабатывающей промышленности в соответствии с универсальноквантифицированной характеристикой состояния информационной среды // Вестник Алтайской академии экономики и права. 2020. № 12-3. С. 621-637.

27. Gross domestic product per capita based on purchasing-power-parity in current prices.- Текст: электронный // Knoema: [сайт].- URL: https://knoema.com/atlas/United-States-of-America/GDP-per-capita-based-on-PPP (дата обращения: 05.11.2020).

28. Number of poor at $\$ 5.5$ a day based on purchasing-power-parity. - Текст: электронный // Knoema: [сайт]. - URL: https://knoema.ru/atlas/Соединенные-Штаты-Америки/topics/Бедность/Численность-бедного-населения/ Number-of-poor-at-dollar55-a-day (дата обращения: 05.11.2020). 